Francesco Mauro

Luca Braidotti

Giorgio Trincas

http://dx.doi.org/10.21278/brod70301

\title{
DETERMINATION OF AN OPTIMAL FLEET FOR A CNG TRANSPORTATION SCENARIO IN THE MEDITERRANEAN SEA
}

UDC 629.5(05): 629.56: 629.5.545: 629.5.01

Original scientific paper

\begin{abstract}
Summary
For the natural gas transportation, several technologies can be applied, having different effectiveness and costs depending on the analysed case. The Mediterranean Sea is presenting a typical scenario where compressed natural gas $(\mathrm{CNG})$ transportation is particularly attractive compared to liquefied natural gas (LNG) and pipelines, not only for stranded gas shipping but also for transportations cases where CNG is usually representing the most economically convenient solution. Approaching the design of a CNG ship is not an easy task, since the pressure vessel (PV) technology is strongly influencing the ship layout and hull form. Here an enhanced conceptual design method is adopted; taking into account the economic-financial issues together with logistics, in order to determine the best fleet composition selecting the best ships for the selected scenario. The ships composing the fleet are supposed to load/offload the natural gas on buoys; hence, dynamic positioning (DP) will also be considered as an attribute in the evaluation of alternative designs. As final outcome of the enhanced concept design process it will be possible to speed up drawing of the preliminary lines plan and general arrangement plan of the sister ships composing the fleet.
\end{abstract}

Key words: $\quad$ CNG transportation; Conceptual design; Optimal fleet composition; Dynamic positioning; Shipping tariff

\section{Introduction}

Nowadays hydrocarbons are still the main source for energy production around the world, covering almost the $80 \%$ of the total energy production [1]. Natural gas, among all available hydrocarbons, is for sure the most environmental friendly solution for energy production and it is believed that it will be continuously more employed for production with an estimated annual rate of $2.2 \%$ from 2015 to 2050 . Already in 2025, the natural gas production will grow up to 151 trillion cubic feet (tcf), being almost 70\% higher than global production in 2001 [2]. The growing necessity to access the gas resources requires more flexibility for the exploitation of the considered resource [3]. In particular, especially for maritime countries, this flexibility implies to dedicate particular effort also on the gas transportation from off-shore fields to onshore installations [4]. Several technologies can be adopted for natural gas marine transportation. Present means of transporting natural gas to the markets consists primarily of 
pipelines and liquefied natural gas (LNG), the former accounting for $71 \%$ of all internationally traded gas volumes with the latter making for the rest.

Pipelines are usually the most efficient way to supply natural gas to a final on-shore user. However, its adoption for offshore purposes is limited by the huge installation costs and durable investments, making the offshore pipelines costs up to ten times higher than on-shore ones. The final costs are then influenced by the distance between the gas source and the end user, the water depth and the seabed orography. On the contrary, whichever marine gas transportation mode avoids these kind of restrictions, removing the physical tie between producer and buyer, resulting in a more flexible solution even for the spot market [5].

However, due to the continuous research on the pressure vessels (PV) materials [6], the compressed natural gas $(\mathrm{CNG})$ transport is starting to be really attractive $[7,8]$ and economically competitive also on medium-long distances and large gas volumes, where, traditionally, LNG has always been the most economical solution. CNG is also attractive because of the absence of costly infrastructure facilities such as liquefaction and regasification plants. In fact, in terms of infrastructures, a CNG supply chain only requires submerged turret loading (STL) systems and single point mooring (SPM) discharging systems, which are less expensive than LNG facilities. For such a reason, being CNG competitive also for stranded gas transportation, it can be stated that, in the near future, CNG technology will be the most flexible solution for natural gas transportation.

Marine CNG might be studied as ideal solution for gas trading in several areas around the globe $[9,10]$, where trade links are all within a transport range from 800 up to $2500 \mathrm{~nm}$, which can be considered as the economic competitive range for fleets composed by CNG ships $[11,12]$. Then, to efficiently minimise the shipping tariff for the specific trade scenario, the definition and selection of an optimal fleet for CNG transportation becomes of primary importance $[13,14,15]$. An alternative approach was proposed [16], where the best CNG ships of different size and hull form characteristics can be identified, and then, according to the specific boundaries and constraints, the best solution is identified in terms of economic effectiveness.

Whatever approach is used to handle the CNG marine transportation, the success of the gas value chain is given by the adoption of a feasible and sufficiently accurate concept design process. It is well known that most of the total ship lifetime cost is driven by the decisions taken in the concept design phase [17]. Therefore, putting even more effort in this phase will be extremely favourable for the final economic effectiveness of the gas transportation. For this purpose, an enhanced concept design process [18] is adopted throughout this work, to study the optimal fleet composition for CNG transportation. In the specific case of a CNG ship [19], this kind of approach is mandatory since, due to the continuous developments in the storage technologies and pressure vessels' materials (see Table 1), there is the necessity to design neverbuilt ships, without having any comparable reference.

By means of an accurate concept design, different concurrent solutions for several subsystems can be easily compared [20], identifying the most competitive one.

Table 1 Pressure vessels types and characteristics

\begin{tabular}{|l|c|c|c|}
\hline PV (250 bar) & $\boldsymbol{D}_{\boldsymbol{P V}}(\mathbf{m})$ & $\boldsymbol{W}_{\boldsymbol{P V}}(\mathbf{t} / \mathbf{m})$ & Material \\
\hline Type I & 1.00 & 0.86 & Full steel \\
\hline Type II & 0.95 & 0.71 & Full steel \\
\hline Type III & 2.35 & 0.81 & Steel liner wrapped with composites \\
\hline Type IV & 2.34 & 0.72 & Full composites \\
\hline
\end{tabular}




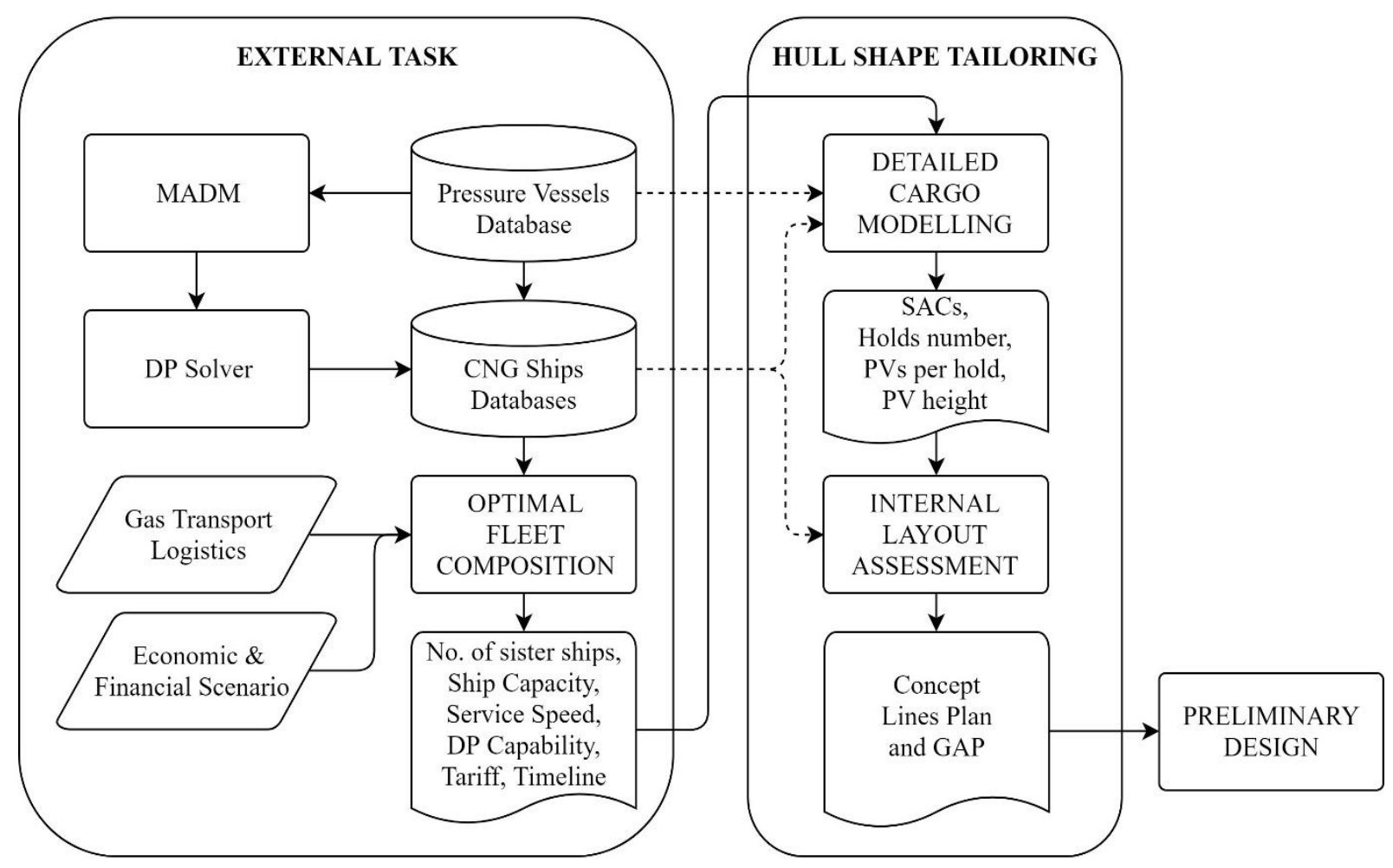

Fig. 1 Enhanced concept design methodology applied to CNG ships fleets.

Here, a possible scenario of natural gas transportation in the Mediterranean Sea is presented, assuming an economic/financial scenario referred to the gas shipping between Zohr field (Egypt) and Brindisi (Southern Italy) with Type III PVs. Since the ships' loading phase is performed through an STL system, also dynamic positioning (DP) has been considered during the concept design phase, evaluating the station-keeping ability in specific conditions and using it as a constraint in the selection procedure.

\section{Design Methodology}

With the aim of selecting the "best possible" fleet capable to transport gas in a given operative scenario, the Multiple Attribute Decision Making (MADM) approach has been adopted as concept design methodology of CNG ships. With this approach, a huge number of different concept solutions can be generated and then the "best possible" concept design is selected through a dedicated evaluation process. The outcome of the process has a strong connection to the operative scenario and can be assumed as basis for the next design phases.

In the present study, MADM has been used to build two databases of "best possible" CNG ships characterized by different gas capacities (from 50 to $900 \mathrm{mmsfc}$, in steps of 50 mmsfc) and different propulsion system. Type III PVs of $2.35 \mathrm{~m}$ diameter at 250 bar have been chosen as gas containment system for all the ships. Then, in the so called external task, the best fleet composition is assessed in order to minimise the gas shipping tariff. Concurrently, the corresponding number of sister ships, their capacity and service speed are determined according to logistics constraints. Furthermore, the internal cargo layout is perfected by defining the sectional area curve at both design draught and tank-top height. With this approach, the number and length of pressure vessels are more accurately assessed and a concept lines plan and general arrangement are generated [18] in order to speed up the transition to preliminary design. The whole concept design process is provided in Figure 1. 


\subsection{Generation of ship database}

In the frame of the MADM approach, each design can be represented by a point in the design space spanned by the design variables as well as by a point in the attribute space spanned by the design attributes [21]. The design generation process maps the variables space to the attributes space by means of a Mathematical Design Model (MDM). A number of modules, which are related to functional decomposition of the ship, where detailed requirements and functions are grouped together, composes the MDM. The MDM is driven by an adaptive Monte Carlo sampling which generates a large number of different designs (i.e. sets of variables' values) within a bounded design space. Through the MDM, the ship properties (attributes) corresponding to each design are assessed from variables and parameters.

Then, the selection process starts. The feasible design sub-space in the attributes space is defined by the application of constraints on design properties. Then, the feasible designs are filtered for dominance, i.e. filtering the Pareto set through metrics of attributes values' distance from the identified ideal point. The preferred non-dominated solutions are then identified via a fuzzy ELECTRE method [22]. In order to better explore the attribute space, further solutions are generated in mini-cubes around the preferred non-dominated designs through fractional factorial design (FFD). The best possible design identified for a selected capacity is added to the database.

It is worth noticing that, in MADM, the selection of variables, parameters, attributes, and constrains, as well as the definition of design space should be carefully carried out by the design team. In the present study, the design model is structured around the following free variables:

- Length between perpendiculars $\left(L_{B P}\right)$;

- Beam $(B)$;

- $\operatorname{Draft}(T)$

- midship section coefficient $\left(C_{M}\right)$;

- vertical prismatic coefficient $\left(C_{V P}\right)$.

These variables are considered sufficient to define the ship accurately and uniquely at the concept design stage, since other hull form characteristics are derived by means of regressions on specific ship database from the above mentioned variables. Furthermore, some technical constants, the so-called parameters, are determined outside the model and consequently remain fixed in running generation of all the alternative designs. They can be classified as shape and size parameters, topological parameters and positioning parameters. As the MDM has to represent the ship in a simple but meaningful manner, a Design of Experiments (DoE) was performed to reduce the number of significant design variables by running different sample runs [13]. In order to restrain the model from shifting to infeasible regions of the design space, design variables are not completely free since, in addition to lower and upper bounds, they may be constrained by dependencies with each other.

Design attributes are principal elements for decision making defining the performances and characteristics of the generated ships. Based on the attained level of the attributes, designs will be accepted or rejected from further analysis. Number of attributes may be as large as needed. Attribute values, which usually have different units of measurement, are normalized via fuzzy sets before entering the dominance analysis. The upper and lower limits of satisfaction for each attribute are provided by the design team. Most of the attributes are calculated via metamodels [23]. Search and optimisation algorithms were used to find the metamodels of ship response functions which are represented by multi-linear regression equations on the predictors.

The main metamodels included in the MDM in order to assess attribute values refer to:

- identification of main dimensions and geometrical coefficients viable to install the pressure vessels adequate to transport the required volume of $\mathrm{CNG}$; 
- selection of length of pressure vessels with given internal and external diameter under the following crisp constraints for the ship: compliance with intact and damage stability rules, roll period greater than 13 seconds to avoid resonance between roll and wave periods, and avoidance of coupling lateral and vertical motions;

- assessment of midship section structure and lightship weight breakdown;

- power prediction in calm water and in a seaway;

- analysis of intact and damage stability for compliance with IMO rules;

- electric power balance;

- seakeeping assessment for added resistance, motions and accelerations;

- powering and gas consumption prediction at different speeds in a round voyage (cycle);

- total time to perform a cycle;

- one-dimensional vibration calculations to avoid risk of resonance between main modes of hull vibration and propellers speed;

- round-trip modelling;

- DP during STL/SPM connection/disconnection and simultaneous power required for gas compression during loading/offloading operations.

To prevent the design from attaining some unwanted characteristics, all intermediate and final results are subject to constraints which are linear and nonlinear equations of the equality and inequality type. Some relationships between geometrical variables and parameters are used as min-max constraints. In principle, constraints are used for hard type of decisions to distinguish between feasible and unfeasible designs, verifying that the solution remains within allowable design space. Attributes, which are design performance measures, are in fact constraints since their values may be constrained; hence, they may be considered as soft (fuzzy) constraints. In particular, a minimum DP capability was set, requiring ships to withstand at least to head seas (15 deg heading) assuming a wind speed of $20 \mathrm{kn}$.

\subsection{Hub-and-Spoke scheme}

It is well known that two major distribution patterns, namely hub-and-spoke and milkrun, are envisaged for CNG marine transportation. In this paper, only the first pattern is considered.

Altogether, four types can be distinguished for the hub-and-spoke scheme:

- Continuous-Continuous (CC): no storage facility is available;

- Continuous-Interrupted (CI): storage facility at receiving point to accelerate the offloading phase;

- Interrupted-Continuous (IC): storage facility at the origin point to speed up the loading phase;

- Interrupted-Interrupted (II): storage facilities at both source and destination points.

Table 2 summarizes the minimum ship capacity and storing capacity required for a given transportation scenario, where:

- $G_{n}$ is the minimum ship capacity;

- $n$ is the number of ships entering the fleet;

- $Q_{\text {in }}$ is the loading rate; 
Table 2 Hub-and-spoke schemes

\begin{tabular}{|l|c|c|}
\hline Distribution Pattern & Minimum ship capacity & Minimum storage capacity \\
\hline Continuous-Continuous (CC) & $G_{n}^{C C}=\frac{T_{r t}}{\frac{n-1}{Q_{o f f}}-\frac{1}{Q_{o n}}}$ & no storage facility \\
\hline Continuous-Interrupted (CI) & $G_{n}^{C I}=\frac{Q_{u} T_{r t}}{n-\frac{Q_{u}}{Q_{o n}}-\frac{Q_{u}}{Q_{o f f}}}$ & $S_{n_{\text {spoke }}}=G_{n}^{C I}\left(1-\frac{Q_{u}}{Q_{o f f}}\right)$ \\
\hline Interrupted-Continuous (IC) & $G_{n}^{I C}=\frac{T_{n}^{I C} Q_{h}}{n}$ & $S_{n_{\text {hub }}}=G_{n}^{I C}\left(1-\frac{Q_{h}}{Q_{o n}}\right)$ \\
\hline Interrupted-Interrupted (II) & $G_{n}^{I I}=\frac{T_{n}^{I I} Q_{u}}{n}$ & $S_{n_{h u b}}=G_{n}^{I I}\left(1-\frac{Q_{h}}{Q_{o n}}\right)$ \\
& & $S_{n_{s p o k e}}=G_{n}^{I I}\left(1-\frac{Q_{u}}{Q_{o f f}}\right)$ \\
\hline
\end{tabular}

- $Q_{\text {off }}$ is the offloading rate;

- $Q_{u}$ is the consumption rate;

- $Q_{h}$ is the daily supply rate of gas at hub;

- $T_{r t}=4 t_{c}+2 L / V$ is the time spent to complete a gas distribution cycle (total roundtrip time), being $t_{c}$ the time needed for connecting/disconnecting the ship to/from the buoys, $L$ the distance from the source site (hub) to the destination site (spoke) and back after gas loading, and $V$ the unknown service speed;

- $T_{n}{ }^{I C}=G_{n}{ }^{C C} / Q_{o n}{ }^{I C}+G_{n}{ }^{C C} / Q_{o f f}$ is the actual cycle time if there is a storage at the destination site;

- $T_{n}{ }^{I I}=T_{n}{ }^{I C}\left(Q_{o n}{ }^{I I}-Q_{h}\right)$ is the actual cycle time if there is a storage at both the origin and destination site.

The loading and offloading rates depends on the facilities available on-sites (e.g. gas grid, compressors, storage, etc...). It has been demonstrated [13] that the overall capacity of a CNG fleet, $G_{f}=n G_{n}$, which substantially has to satisfy shipping of the natural gas available at the origin, is bounded by a lower and an upper limit, respectively, as:

$$
\frac{n}{n-1} T_{r t} Q_{u} \leq G_{f} \leq \frac{n}{n-2} T_{r t} Q_{u}
$$

depending on the gas consumption rate, $Q_{u}$, which can be actually absorbed by the destination terminal. It results that $\mathrm{CNG}$ fleets require two ships $(n=2)$ at least to ensure continuity of gas delivery. Of course, that holds also in the CC scheme where the offloading rate has to equal the daily consumption rate as per Table 2. Intermittent supply and/or delivery (CI, IC, II schemes) results in less ships composing the fleet, or at least in a fleet with the same number of ships but of reduced size, with corresponding lower Capex and Opex and lower shipping tariff.

\subsection{Selection of the optimal CNG fleet}

In last decades, there has been a steady increase in the number of optimisation studies carried out for new buildings. However, in the CNG business, as a rule, the approach has not only to be concerned with optimising one single ship, but must be aimed at formulating 
optimum fleet for a particular transport of natural gas. Different feasible fleets may well have the same annual cargo capacity, while being made up of ships of varying sizes and different service speeds. Enlarging what stated by Lamb [24], the fleet success substantially depends on its economic success. In evaluating different feasible fleets for CNG marine transport, the optimal (preferred) fleet will be that one which requires the minimum tariff to transport an energy unit (USD/mmBtu).

The optimal CNG fleet composition is strictly connected to the operative scenario, techno-economic characteristics of feasible ships, costs and feasibility of infrastructures, the financial parameters (loans, interest rates, period of reimbursement, depreciation allowances, etc.). Scope of the implemented decision-making process is to establish simultaneously the number of sister ships entering the fleet, as well as to simultaneously identify their capacity and economic service speed, in order to transport a specified volume of gas per year from loading terminal (both onshore and offshore) to destination terminals while achieving the expected rate of return. The definition of the shipping scenario is completed by the distance to the market, the stand-by time, the connection/disconnection time on/from the buoys, the loading and offloading rates, and the possible storage facilities at both and destination sites. Several studies $[4,7,13]$ have highlighted that all these parameters have a strong influence on the best fleet composition and must be taken into account simultaneously.

The main logistic constraint in optimising the CNG fleet composition is to ensure that the delivery site is always supplied with the required volume of gas by a ship during the time other $\mathrm{CNG}$ ships are on a round-trip from the destination site to the source and back. The loading and offloading rates play a relevant role in the optimal fleet selection. The identification of the best rates depends on many factors of both technical and economic nature. These rates are strictly correlated to the number of ships in the fleet and to ship capacity. For instance, in the interrupted-continuous scheme the loading rate is solved through the following equation

$$
Q_{o n}^{I C}=\frac{G_{n}^{C C} Q_{o n}}{n G_{n}^{C C}-G_{n}^{C C} \frac{Q_{o n}}{Q_{h}}-Q_{o n} T_{r t}}
$$

which could be solved by means of a constrained multiobjective optimisation method.

On the contrary, the authors' strategy has been to establish a set of possible values for loading and offloading rates and to determine the sub-optimal fleet for each couple $\left(Q_{o n}, Q_{o f f}\right)$ by identifying the feasible sister ship previously stored in a database. Then, the optimal fleet is selected as the sum of ships extracted from the database, requiring the minimum total tariff, e.g. the shipping tariff plus the extra cost incurred by the infrastructure facilities.

Even in the simplest hub-and-spoke distribution pattern, e.g. continuous-continuous service, avoiding concurrent consideration of logistics and conceptual designing of ships with simultaneous merging of technical and economic properties can lead to wrong decision making. Availability of a database of CNG ships with different capacity and evaluated in technoeconomic terms at different service speeds is a must in searching for the optimal CNG fleet while complying with the aforementioned logistic constraint.

\subsubsection{Cashflow model}

Especially in concept design, which impacts on total building cost for $70 \%$ at least, cost estimation of alternative technical solutions is a decision making tool of paramount importance. The engineering economics constitutes a basic element of the shipping strategy since optimisation of a fleet composition cannot be a mere technical problem. Economic prognoses constitute the input from which any selection method concludes to an optimal decision making. 
In order to evaluate a shipping tariff, a built-in economic model provides monetary value of each alternative CNG project from a shipowner's financial prospective. Ship costs include the costs from the shipyard, the cost of the operating cycle and elements of cost of the ship through its economic life. Clearly, the cost of construction and operation will affect the shipping tariff, but the financial conditions in the market will have an equally important impact. It is the relationship between the two which forms the conceptual basis for the economic model implemented for decision making about CNG fleet composition.

The most popular tool for analysis of engineering economics is a Discounted CashFlow (DCF) model, which allows to determine the Net Present Value (NPV) for an expected rate of return and over the assumed project life. Discounting allows for the time value of money, which is an effective tactic for evaluating the future value of a project in terms of today's money. The decision criterion for investment selection is the NPV which can be represented by a linear function of the economic variables, that is, the object function which is the sum of the discounted annual cash flows. Cash flows are calculated on an after-tax basis and are assumed to occur on an end-of-year basis. In formulating the NPV equation, the fiscal depreciation of every ship is established by the linear method on the basis of the scrap value at the end of the ships' estimated economic life. On the basis of NPV evaluated for each feasible fleet, it is straightforward to determine the best fleet composition, e.g. that one which requires the minimum tariff for unit energy transport by setting NPV $=0$ for the expected rate of return to the shipowner.

Calculation of DCF involves deduction of running costs and capital costs from assumed revenue earned. What is left from annual income after these expenditures and amortisation is generally subject to taxes. Income is assumed as the amount of money the shipping company gets for shipping the gas between the origin and destination points. While income is assumed constant year-to-year, some running costs (crew and victualing, maintenance, administration) are escalated over time.

Running costs cover:

- operating costs related to the daily running of the ship (crew, lubricants, stores and consumables, routine maintenance and repairs, insurance, administration), assumed to represent an Italian registered ship with national crew

- voyage costs (gas consumption from main engines and auxiliaries, gas price at wellhead),

- CNG handling costs.

Capital costs include:

- capital repayment (loan to finance the project, terms of loan),

- interest payments (source of loan, interest rate, terms of loan),

- periodic maintenance (age of ship, survey cycles, class regulations, maintenance policy).

Many assumptions are made when calculating the profitability of a CNG fleet. Material costs of the ship are difficult to estimate accurately as public prices from manufacturers are usually not available Moreover, since CNG ships belong to a quite novel concept, cost estimate of some special features of the ship like gas containment system are necessarily imprecise. Operational cost calculations are somewhat less inaccurate. 


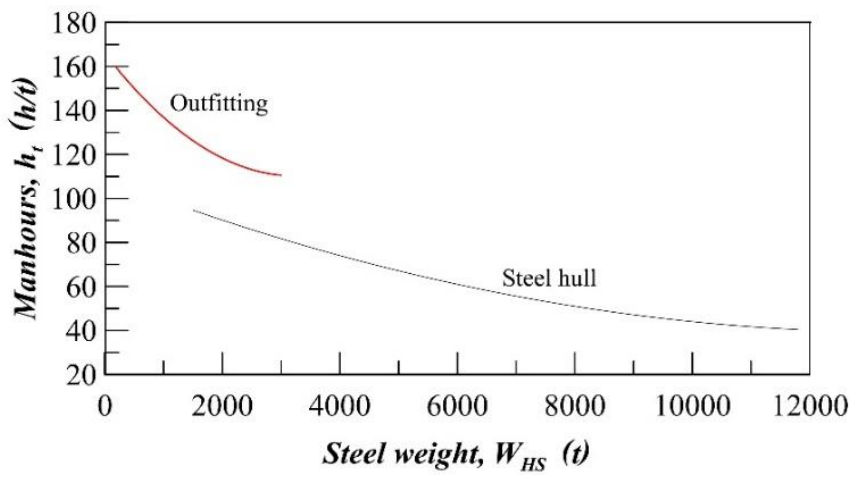

Fig. 2 Manhours per tonne of steelwork and outfitting in Italian shipyards

\subsubsection{Capex}

The cost estimate for building an innovative ship and infrastructure facilities (Capex) is performed with a top-down approach for main items by project elements and then by discipline. Each discipline contains details as to outline of the cost estimate breakdown structure, technical data sources, cost data sources and contingencies. Transferring the gas from the production facility to the CNG containment system on board is technically straightforward and requires a minor capital investment for a short subsea pipeline, riser pipes and gas transfer buoys. On average, $5 \%$ and $6 \%$ of the total investment on the CNG project is expected for loading and offloading terminals, respectively.

As regards the ship building cost, it is evaluated distinguishing between material costs, direct labour costs and overheads, including an expected profit margin by the shipyard. Breakdown of the material cost covers technological main groups such as hull structure, superstructure, engine rooms, propulsors, electrical plant, electronics \& control system, auxiliary systems, outfit and furnishings, special systems. Cost of the pressure vessels is included depending on their number and length. Finally, a CGT (compensated gross tons) factor pertaining to an LNG ship of the same size is applied.

At concept design stage, based on statistics of LNG/LPG ships the ship acquisition cost in US dollars can be formulated as:

$$
C_{a c q}=10^{3}\left(C_{H S}+C_{M}+C_{E}+C_{P V}\right)(1+p)
$$

where $C_{H S}=3.365 W_{H S}{ }^{-0.224}$ is the hull steel cost as a function of steel weight $W_{H S}$ in metric tonnes, $C_{M}=14.308 P_{B}{ }^{0.669}$ is the machinery and auxiliaries cost depending on engines brake power $P_{B}$ in $\mathrm{kW}, C_{E}=14.770 W_{O D}{ }^{0.932}$ is the equipment cost depending on outfitting, heating, ventilation, air conditioning, electric plant and deck machinery cost depending on their weight $W_{O D}$ in metric tonnes, $C_{P V}$ is the total cost of the containment system (pressure vessels, piping, compressors, etc.), $p$ is the profit margin of the shipyard, in percentage. It is worth noticing that cost of pressure vessels is strictly confidential.

Manhours are the basis of all labor costs, and once estimated, it is only necessary to apply wage rates, overheads and yard profit to arrive at the total labor costs. At the simplest level deemed as sufficient at concept design stage, steelwork labor cost $C_{h}$ can be estimated from:

$$
C_{h}=W_{H S} h_{t} c_{h}
$$

where $h_{t}$ is manhours required for each steel tonne, $c_{h}$ is the wage rate per manhour. It is worth noticing that manhours depend on steel weight, ship length, block coefficient and compensated gross ton coefficient. Productivity data available from an Italian shipyard made it possible to derive the regression relationships for manhours (Fig. 2) distinguishing between structures and outfitting building. 
An average reduction factor is given to evaluate economics of scale for multiple ship production, considering the elimination of nonrecurring needs, such as drawings and templates, and considering the improvement resulting from the learning of the labour force.

\subsubsection{Opex}

Operating costs are the ongoing expenses which include most of the daily operational costs during the ship lifetime, but excluding the gas (fuel) which is assumed to be included in the voyage costs. The operation costs of the ship are divided in three main categories: fuel costs, personnel costs, and maintenance.

Fuel costs are estimated based on the operational profile calculated earlier. Crew salary costs are estimated based on the number of personnel onboard and their jobs. There are 20-25 crew members (captain, three officers, seamen). In addition to basic salaries and wages, personnel costs include basic salaries and wages, victuals, social insurance, repatriation expenses, recruitment and training cons. Maintenance costs are divided into hull maintenance, engine maintenance and general maintenance. Engine maintenance is assumed to cost about $3750 \mathrm{USD} / \mathrm{kW}$ per year, whereas general maintenance is assumed to cost $0.5 \%$ of ship total price per year. Insurance costs are assumed to be $1.2 \%$ of ship total price per year.

In the overall maintenance cost, a significant part is on the dry-docking cost $C_{D D}$. It has been estimated as [25]:

$$
C_{D D}=a+b y+c D W T+d S D+e P_{B}
$$

where $y$ denotes number of years from the date the ship is delivered, DWT its deadweight and $S D$ are the days from the ship's arrival date to the yard and the departure date. The coefficients in the regression formula have been determined from data on a number of chemical carriers with deadweight below 30,000 tons.

\section{Operative scenario and financial parameters}

The case study is centred on the specific case of the gas shipping in the Mediterranean Sea area, from North Africa to Europe. More in detail, the case of gas transportation between the offshore field of Zohr, part of the Egyptian economic area, and the South of Adriatic Sea (Brindisi). The selected scenario is representative of a source-destination distance of about 1000 $\mathrm{nm}$ and a production rate of 2 billion cubic meters of gas $(\mathrm{bcm})$ per year.

A hub-and-spoke continuous-continuous service scheme is adopted, assuming a constant service speed, to be determined as economically optimal, over the entire voyage. Furthermore, the following assumption have been set:

- Loading/offloading rate: $5 \mathrm{mmscm} / \mathrm{d}$, where $4 \mathrm{mmscm} / \mathrm{d}$ is the delivered capacity;

- STL connection and SPM disconnection time: 1.5 hours per operation;

- Operating days per year: 355 (as required by rules, the CNG ships will be taken out of service for dry-docking once every 5 years for 40 days and at each 30-month intermediate point for about one week during an underwater survey; this totally amounts to about 50 days in 5 years).

In addition, in order to properly take into account unpredictable situations that might occur to the ship during its lifecycle, each one-way voyage duration is rounded up to the nearest half-aday time.

Furthermore, in the present case study, the following financial assumptions are made: monetary values at a base value of 2018 US dollars and an inflation rate of $2 \%$ for revenues and expenses, a 30\% corporate income tax; linear depreciation of ships for a period of 15 years. Capital for ship building will be acquired through both equity and debt, at a rate of $30 \%$ equity to $70 \%$ debt. The loan term is assumed to be 8 years at an interest rate of $5.5 \%$. 
Interest payments begin at the end of the project's initial year. For the three years of the CNG ships' construction, the principal repayment is assumed to be $40 \%, 30 \%$, and $30 \%$ of the total project cost. The expected rate of return for the CNG project is assumed to be $12.5 \%$, a reasonably fairly standard value for the oil \& gas companies. Italian shipyards average hourly cost has been assumed in building cost estimation, whilst daily operating costs were derived from average data for LNG ships, while fuel costs from present market information concerning price of natural gas at wellhead.

\section{Propulsion systems}

Different propulsion systems installations have a remarkable effect on shipping efficiency when applied on CNG ships [20]. The impact on hull forms (not limited on the aft-body), propeller design and general arrangement, should be taken into account since the concept design stage. Moreover, since natural gas is flammable and potentially explosive, the application of redundant propulsion systems and steering gears is advisable. Thus, the single screw propulsion system should be avoided in favour of twin-screw arrangements. In the present study, a comparison between two alternative twin-screw solutions is carried out highlighting the effect on the required freight rate (tariff) and DP capability. The first solution is a twin-skeg ship with conventional mechanic propulsion driven by 2 -stroke dual-fuel engines. The second is a full diesel-electric solution with pods. In this section the two propulsion systems are briefly described highlighting the differences and peculiarities rising up in the ship modelling during concept design stage.

\subsection{2 -stroke diesel engine system}

The first option under investigation is a conventional propulsion system adopting 2-stroke dual fuel engines as prime movers. Such a solution adopts high efficiency engines, rotating at low speeds to be directly coupled with the propellers. Hence, all the propulsive drive will be extremely essential, reducing the amount of losses from engine brake power $P_{B}$ to propeller delivered power $P_{D}$. However, this kind of propulsion system requires a propeller rotating at low speed. Such a low rotational rate implies utilisation of large diameter propellers, being mountable only in case of a sufficiently high draught. Because of the adoption of light Type III $\mathrm{PVs}$, it is not reasonable to presume to have a high draught even for large capacity ships; for such a reason, in order to keep the propeller diameter under control, the selected hull form for this kind of propulsive solution will be of the twin-skeg type.

This kind of propulsion layout requires a different modelling of the propulsion since conceptual calculations. Although the total resistance in calm water can be evaluated according to statistical methods [26], the determination of propulsive coefficients (especially for wake fraction $w$ ) is not comparable with a conventional twin-screw ship. The presence of the gondola is effectively decreasing the relative flow velocity coming into the propeller disk, leading to values of $w$ more similar to those of single-screw ships. That is why the wake fraction $w$ has been estimated according to an equivalent single-screw statistic method [26], while the thrust deduction factor $t$ was estimated with conventional twin-screw statistical formula [27].

To take into account the actual operative scenario since propeller selection process, also added wave resistance has been included according to statistical formulations [28]. The propeller selection has been carried out with a bounded iterative procedure; considering 4bladed B-Series propellers [29], a maximum diameter $D_{M A X}$ according to hull clearances and a database of 2-strokes diesel engines. Selection of the diesel engine has to ensure the matching between propeller and engine revolution rates. 


\subsection{Diesel-electric system}

Another interesting solution for the propulsive system can be the adoption of a dieselelectric propulsion. The adoption of such a system is required by the installation of pod propulsive devices, which can be considered as an improving solution for the positioning ability of the ship during loading/offloading operations on/from a fixed buoy. Besides, the installation of the pods leads to an aft-body hull form totally different with respect to the twin-skeg, but more similar to a conventional twin-screw ship. It means that the metamodel used to define the geometric hull characteristics in ships generation will be different between the two cases, in order to capture the peculiarities of each candidate hull form.

The propulsive coefficients evaluation in a podded ship can be performed, as first approximation, in the same way of a twin-screw ship. However, a different modelling of kinematics and dynamics coefficients of the propulsors is needed. On this purpose, the reproduction of characteristic thrust and torque curves can be done starting from B-series propeller open water curve and applying a procedure derived from thruster units [30]. Openwater curves have been modified according to the following coefficients:

$$
\lambda_{T}=\frac{K_{T}}{K_{T_{0}}} \quad \lambda_{Q}=\frac{K_{Q}}{K_{Q_{0}}} \quad e_{T}=\left.\frac{J}{J_{0}}\right|_{K_{T}} \quad e_{Q}=\left.\frac{J}{J_{0}}\right|_{K_{Q}}
$$

where subscript $O$ denotes original B-series values. The coefficients as per equation (6) modify the standard open water curve, simulating the behaviour of the complete pod unit. An example is given in Figure 3. The tuning of the coefficients has been performed to reproduce the pod hydrodynamic characteristics given by the manufacturer.

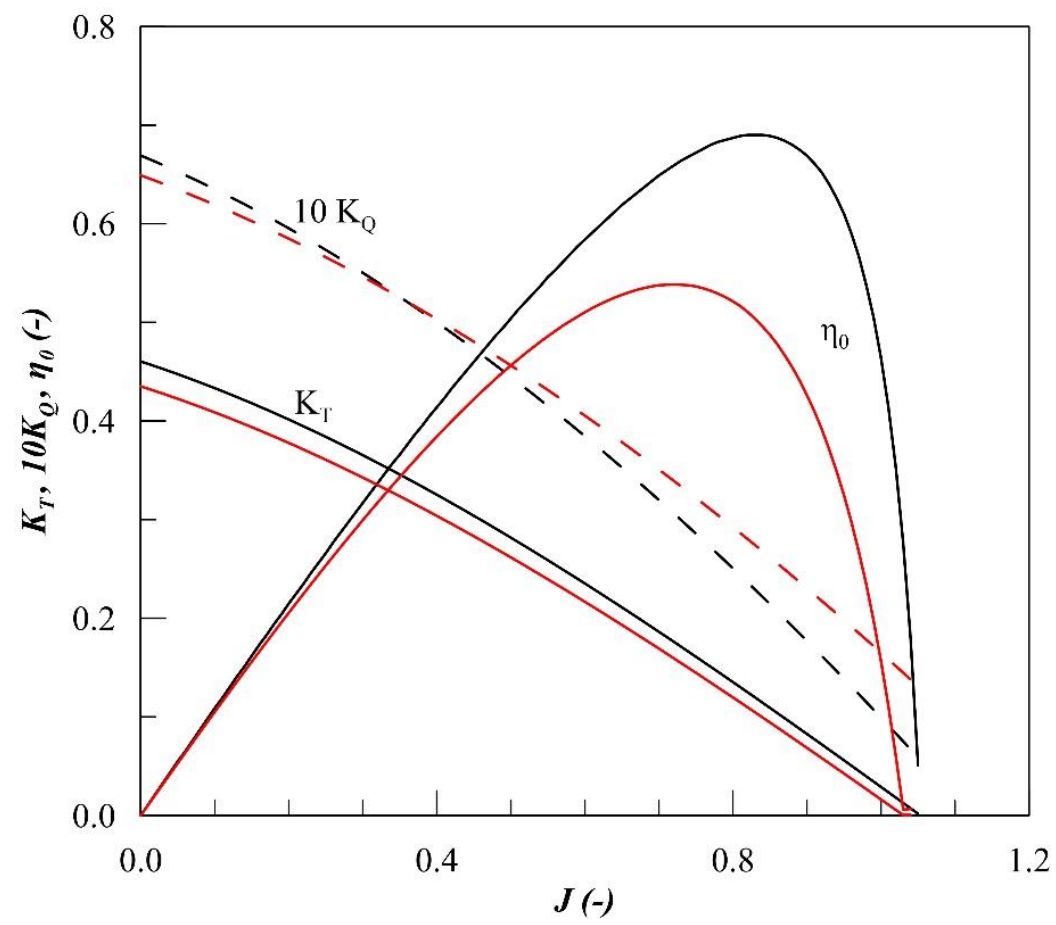

Fig. 3 Open water chart comparison between a B series propeller (black) and equivalent pod unit (red). 


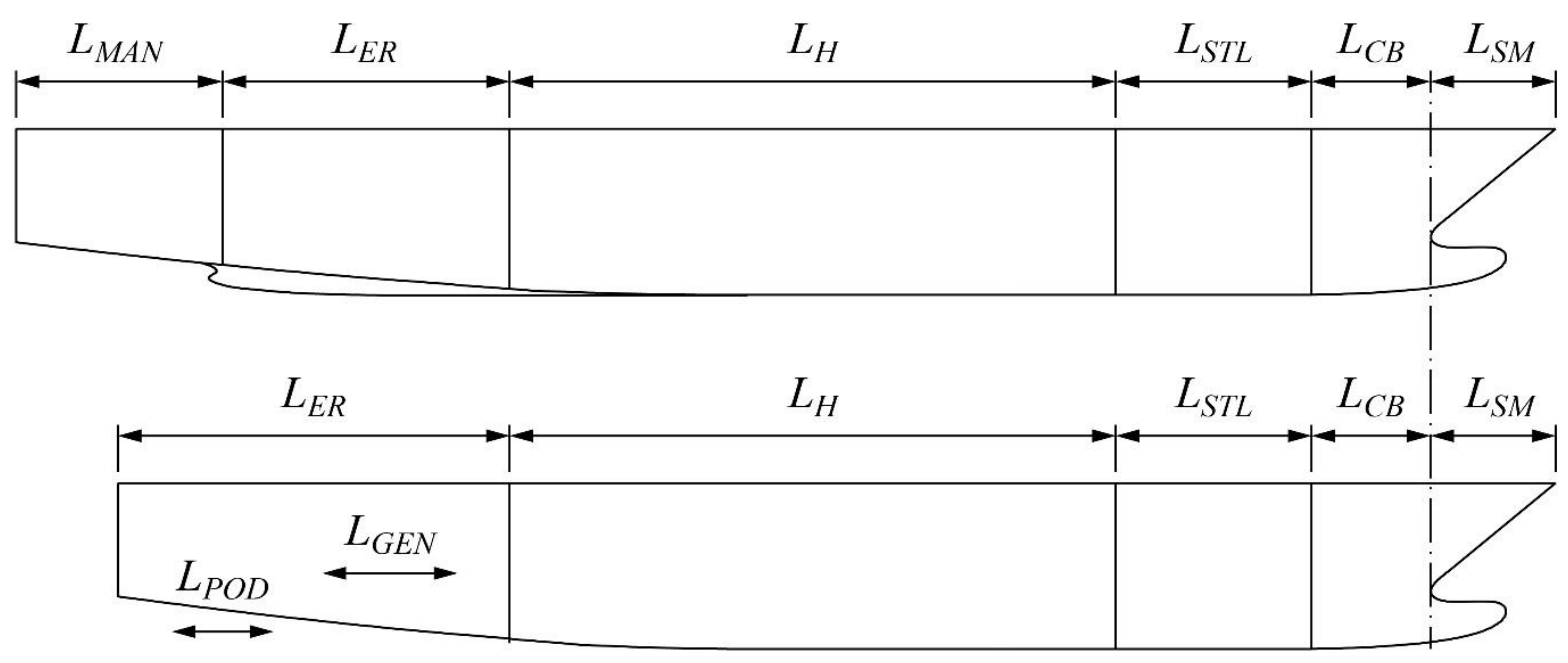

Fig. 4 Length modelling for the two proposed propulsion systems.

\subsection{Concept design ship layout modelling}

The selection of two different propulsive systems influences not only the hull form modelling and algorithms for power performance prediction, but also the internal layout of the ship, hence, the areas needed to fit the engine room and consequently the main dimensions of the ship. As described in [18], the internal layout modelling of a CNG ship can be done as a function of the so-called primitive cargo unit, which for a CNG ship is the PV diameter. Some specific spaces should be taken into account. In fact, besides cargo length and engine room length (common to all the type of ships), other longitudinal spaces should be dedicated to equipment necessary to gas loading and offloading process. This is the case of the conical recess in the fore part of the flat of bottom for connection to the STL system and of the main compressors. For such a reason dedicated space should be considered to install the above mentioned equipment. A schematic representation of the different configurations is given in Figure 4. With such a discretisation, considering the system origin on the fore perpendicular, the length overall $L_{O A}$ definition becomes:

$$
\begin{aligned}
& L_{O A_{\text {twin-skeg }}}=L_{S M}+L_{C B}+L_{S T L}+L_{H}+L_{E R}+L_{M A N} \\
& L_{O A_{p o d}}=L_{S M}+L_{C B}+L_{S T L}+L_{H}+L_{E R}
\end{aligned}
$$

where $L_{S M}$ is the stem overhang length, $L_{C B}$ is the collision bulkhead distance from the origin, $L_{S T L}$ is the STL longitudinal space, $L_{H}$ is the total length of the holds, $L_{E R}$ is the engine room length, and $L_{M A N}$ is the manoeuvring machinery space. It must be noted that in the podded case $L_{E R}$ includes the length of both pods $L_{P O D}$ and gen sets $L_{G E N}$, so that there is no necessity to add an extra space for manoeuvring equipment. The engine room length is then function of the machinery size selected by the mathematical metamodel.

\section{Dynamic positioning}

A CNG ship, as it has been presented throughout this paper, has another issue, e.g. the dynamic positioning, to tackle in order to load/offload the gas in the expected time. In fact, while the ship is stationing on the STL buoy for the gas loading, should keep position and then manoeuvre autonomously [31], thus requiring a DP system. Therefore, the DP issue should be considered since the concept design stage. 
The determination of the capabilities of a DP system is not an easy task and may be assessed typically using two different approaches [32]: a quasi-steady approach and/or a time domain one. The time domain approach $[33,34]$ is used once the available ship details are sufficient to accurately define the whole system mounted on board. This is not the case at the concept design stage, where fast and sufficiently reliable tools should be used to assess the performance of each attribute. For such a reason, a quasi-steady approach [35] has been used to perform station-keeping capability of the ship, where only the equilibrium between the external forces and the thruster delivered forces should be evaluated on the horizontal plane:

$$
\left\{\begin{array}{c}
F_{X_{E N V}}+F_{X_{T H R}}+F_{X_{E X T}}=0 \\
F_{Y_{E N V}}+F_{Y_{T H R}}+F_{Y_{E X T}}=0 \\
N_{Z_{E N V}}+N_{Z_{T H R}}+N_{Z_{E X T}}=0
\end{array}\right.
$$

In system (9), $F_{E N V}, N_{E N V}$ are the environmental, $F_{T H R}, N_{T H R}$ the thruster and $F_{E X T}, N_{E X T}$ the external forces and moments. By modelling the DP in the concept design stage, the external forces have been neglected, since they are related to the mutual interaction between ship and STL buoy, forces that are initially unknown. Since it will be extremely complicated and time consuming to perform a complete DP assessment during a generation process as described in Section 2, it has been decided to restrict the analysis to a single environmental condition and encounter angle. Here, only the 15-deg case is calculated per each generated ship, considering a wind speed of 20 knots and a collinear wave according to IMCA correlation [36] and a 1 knot collinear current speed. By doing that, each generated ship can be accepted or discarded according to the selected criteria. This kind of approach, slightly reduces the calculation time and allows to use more reliable allocation algorithm for the equilibrium resolution.

\subsection{Thrust allocation algorithm}

Between the several possibilities to solve system (9), here an optimisation algorithm has been used, capable to manage non-linear objective functions subject to non-linear constraints [37]. As objective function, the minimum absorbed power has been selected, considering the following non-quadratic formulation:

$$
f(x)=\sum_{i=1}^{n} x_{i}^{3 / 2}
$$

where $n$ is the number of thrust devices and $x_{i}$ are the thrust values delivered by each single device. In the specific, for the total thrust determination, interaction effects have been considered according to ABS indications [38]. Moreover, for the back thrusters of the podded ship, forbidden zones have been implemented to avoid the possibilities of the thruster to work in an excessive interaction zone, due to the presence of the skeg and the other thruster.

In case of the twin-skeg ship, the rudder has been considered of the Becker type, using lift and drag coefficients coming out from literature.

\subsection{Environmental loads determination}

The environmental forces have been modelled in such a way to take into account the effects of wind, waves and current. Since it is difficult to determine in the conceptual design stage the current and wave loads as a function of the main parameters of the ship, simplified methods given by regulations have been applied [39]. As regards the wind loads, a more detailed analysis has been carried out, since more information are available from the scientific literature. 
Several possibilities are available to determine the wind loads in an early-design stage [40], adopting coefficients that depend on the main parameters of the ship superstructures. In literature, different databases are available for direct use of experimentally derived coefficients for wind loads [41]. However, the novelty of the ship type proposed in this study has made it impossible to find a suitable comparable geometry in standard databases. For such a reason other methods have been investigated to determine the wind loads.

Here Isherwood [42], Fujiwara [43] and DNV [39] methods are compared on the standard superstructure layout considered for the two ship types. The methods are using different ways to obtain non-dimensional wind coefficients. Here all the coefficients are represented in the following form to have a homogeneous comparison:

$$
\begin{gathered}
C_{X}=\frac{F_{X}}{0.5 \rho_{\text {air }} A_{T} V_{W}^{2}} \\
C_{Y}=\frac{F_{Y}}{0.5 \rho_{\text {air }} A_{L} V_{W}^{2}} \\
N_{Z}=\frac{N_{Z}}{0.5 \rho_{\text {air }} A_{L} L_{O A} V_{W}^{2}}
\end{gathered}
$$

where $\rho_{\text {air }}$ is the air density, $V_{W}$ the wind speed, $L_{O A}$ the overall length and $A_{T}, A_{L}$ the transversal and lateral area projections respectively. $A_{T}$ and $A_{L}$ are estimated as a function of ship main dimensions and PV length.

In Figure 5, a comparison is presented between the different methods for the two ship types. It can be seen that the Isherwood method is more scattered and is giving the lower values for the maximum loads. The DNV method is giving a really simple trend, being in line with the maximum loads of Isherwood method for lateral winds. The Fujiwara method is giving the higher values for the transverse and lateral forces. It has been decided to adopt the Fujiwara method to perform the DP calculations, in such a way to take a margin on the loads.

\section{Best ships comparison}

The design process described in section 2 has been applied to the operative scenario defined in section 3 leading to assess the best CNG fleet composition for both the twin-skeg and podded ship concepts installing different propulsion systems. Figure 6 shows all the feasible fleets for both the ship families. For each fixed number of sister ships $(5,6,7,8$ and 9 ships), the combination of ship capacity and service speed (from 17 to 24 knots in step of 1 knot) is determining the shipping tariff. Than the minimum tariff can be evaluated per each fleet composed by different number of ships. Comparing the relative minima, the optimum fleet is determined. Some scattering on tariffs between contiguous design solutions is mainly caused by the discrete nature of machinery sizes available on the market. This behaviour is more evident for the podded solution.

For both families of ships, an optimal fleet can be defined, i.e. the one requiring the minimum tariff. In the given scenario, for the twin-skeg solution the best fleet composition corresponds to 6 ships sailing at a service speed of 23 knots, resulting in a total gas capacity of 290 mmscf per ship. As to the podded solution, the diagram presents less evidence for the optimum determination. In fact, there is a range of ship capacities yielding fleets requiring almost the same shipping tariff. Nevertheless, an absolute minimum can be determined corresponding to a fleet of 7 ships with lower service speed of 20 knots and a capacity of 251.6 mmscf. 


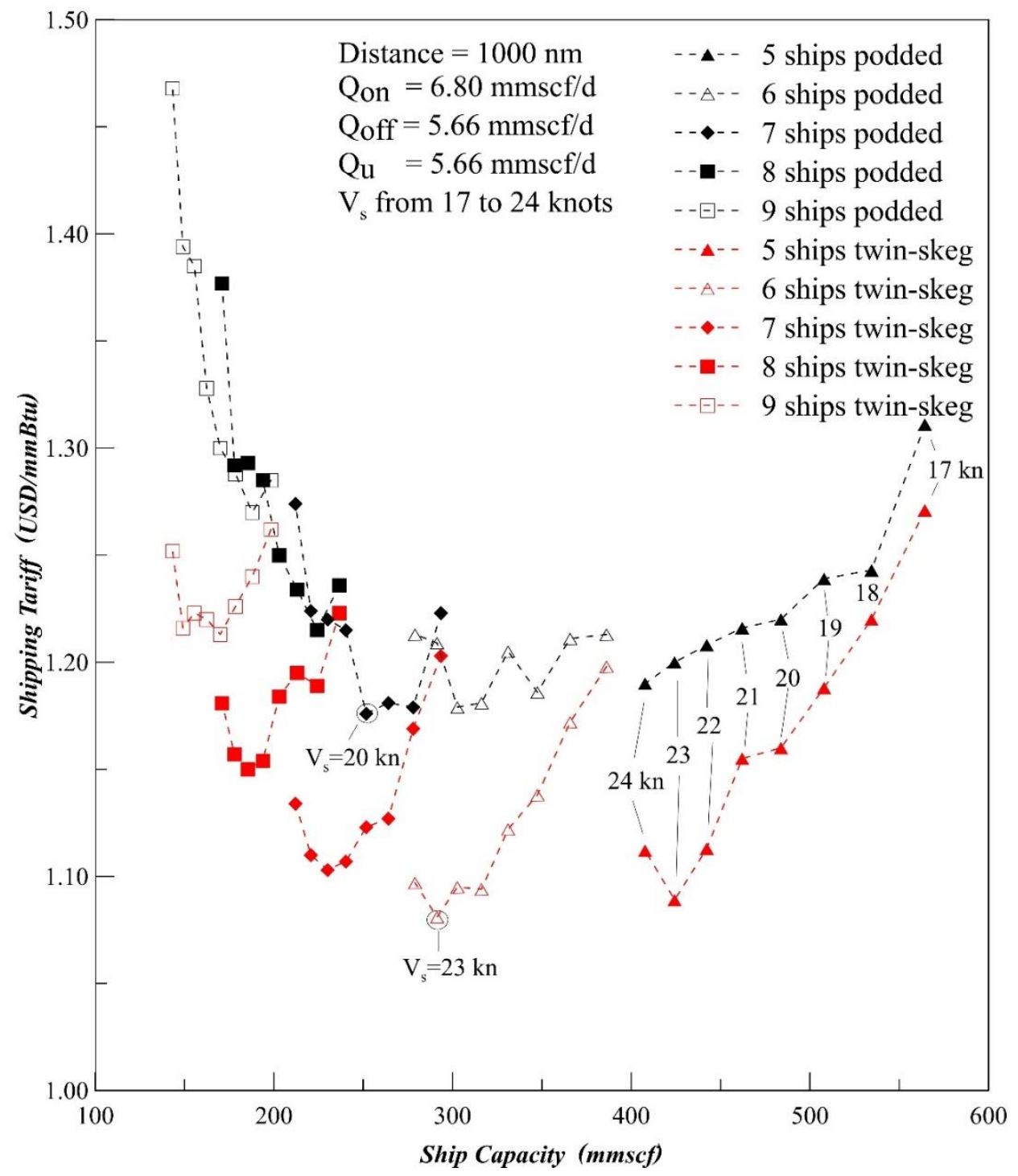

Fig. 6 Shipping tariff for all the feasible fleet composition for both podded and twin-skeg solutions.

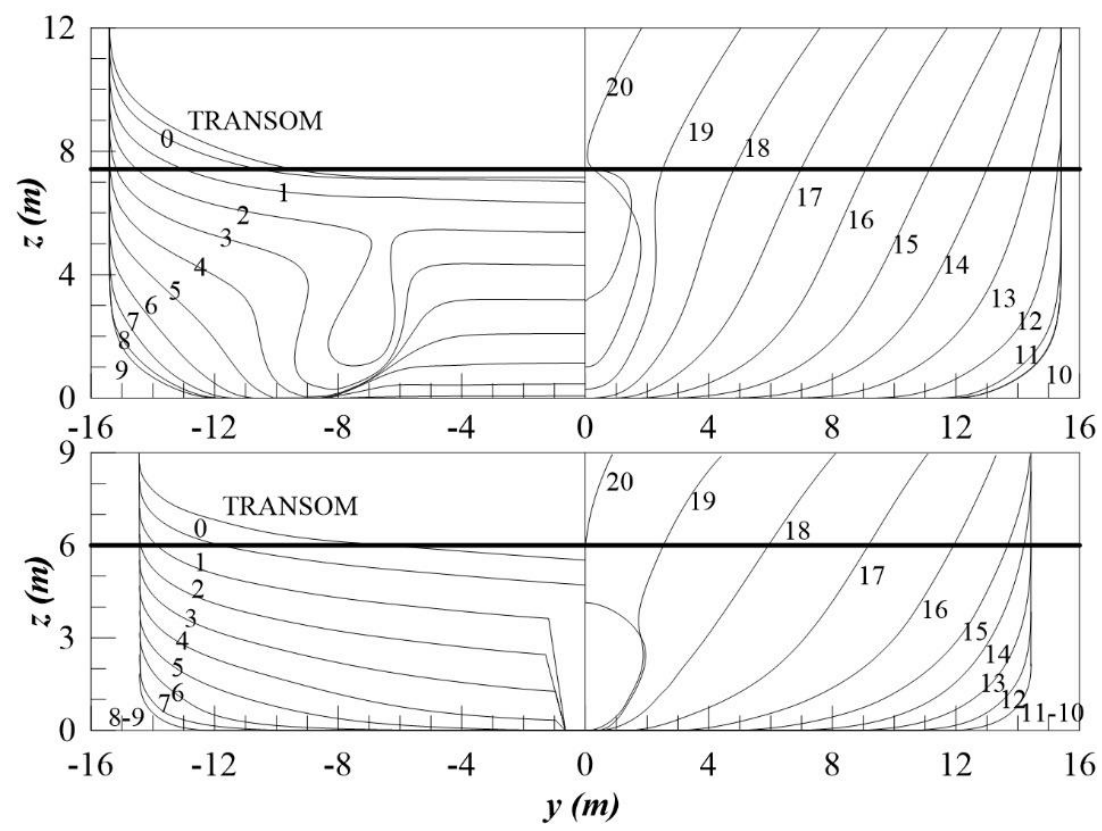

Fig. 7 Body plan of the twin-skeg ship (top) and podded ship (bottom). 


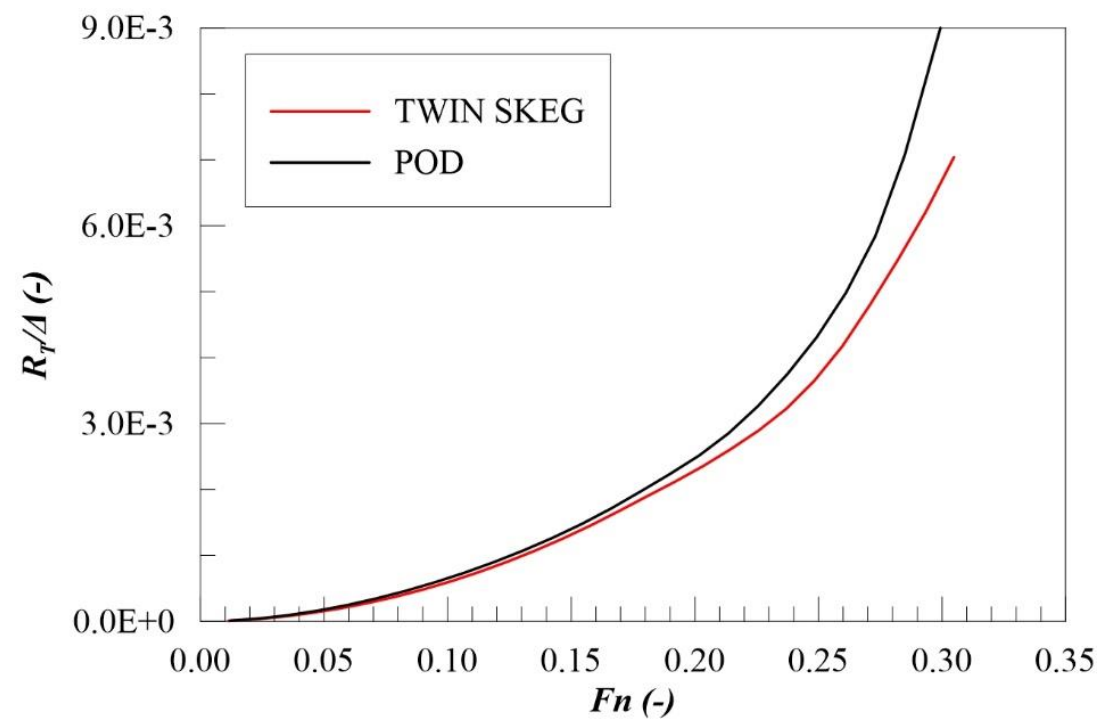

Fig. 8 Specific resistance comparison between the two ship types.

Table 3 Main particulars of the best ships composing the two optimal fleets.

\begin{tabular}{|l|c|c|c|c|}
\hline \multicolumn{1}{|c|}{ Items } & Symbol & Twin-skeg & Podded & Unit \\
\hline Length over-all & $L_{O A}$ & 216.82 & 200.20 & $m$ \\
\hline Length between perpendiculars & $L_{B P}$ & 201.02 & 185.60 & $m$ \\
\hline Breadth & $B$ & 30.82 & 28.86 & $m$ \\
\hline Design draught & $T$ & 7.42 & 6.00 & $m$ \\
\hline Volume of displacement & $\nabla$ & 27950.3 & 22304.5 & $m^{3}$ \\
\hline Prismatic coefficient & $C_{P}$ & 0.622 & 0.710 & - \\
\hline Midship coefficient & $C_{M}$ & 0.978 & 0.978 & - \\
\hline Waterplane area coefficient & $C_{W P}$ & 0.830 & 0.886 & - \\
\hline Transversal projected exposed area & $A_{T}$ & 930.74 & 856.58 & $m^{2}$ \\
\hline Lateral projected exposed area & $A_{L}$ & 4855.98 & 4271.58 & $m^{2}$ \\
\hline Service speed & $V$ & 23.0 & 20.0 & $k n$ \\
\hline Available shaft power & $P_{S}$ & 22304.5 & 19601.0 & $k W$ \\
\hline Propeller diameter & $D$ & 4.80 & 4.35 & $m$ \\
\hline Pitch diameter ratio & $P_{2}$ & 1.325 & 0.874 & - \\
\hline Expanded area ratio & $A_{E} / A_{0}$ & 0.634 & 0.598 & - \\
\hline Blades number & $Z$ & 4 & 4 & - \\
\hline Bow thruster propeller diameter & $D_{T}$ & 2.40 & 2.20 & $m$ \\
\hline Bow thruster nominal power & $P_{T}$ & 1825.0 & 1500.0 & $\mathrm{~kW}$ \\
\hline Ship capacity & $\nabla_{g}$ & 290.0 & 251.6 & $\mathrm{mmscf}$ \\
\hline Number of PV & $N_{P V}$ & 305 & 287 & - \\
\hline Length of PV & $l_{P V}$ & 25.40 & 23.20 & $m$ \\
\hline Delivered gas per cycle & $w_{g d}$ & 4576.9 & 3945.8 & $t$ \\
\hline Gas consumption for propulsion & $w_{g c}$ & 211.6 & 168.1 & $t$ \\
\hline Cycles per year & $C_{p y}$ & 51.5 & 50 & - \\
\hline
\end{tabular}




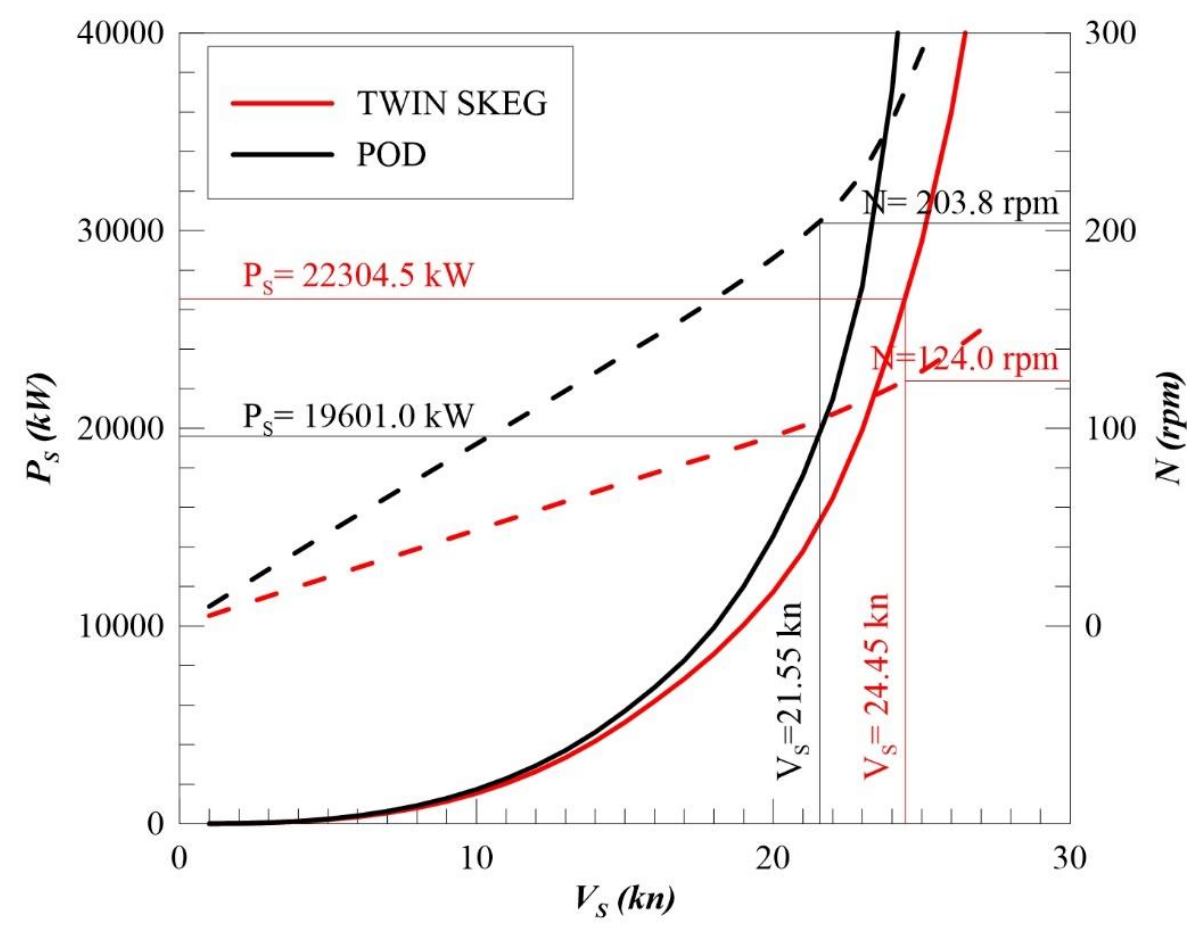

Fig. 9 Speed power prediction at trials condition for the two ships.

In both cases, the service speed corresponding to the minimum tariff for a given number of ships increases as the number of ships decreases. Furthermore, it is worth noticing how, in the same operative scenario, even the number of sister ships changes with adoption of different propulsion systems resulting in very different design solutions in terms of main dimensions, capacity, service speed, etc. All the characteristics of the two optimal ships (Fig. 7) have been assessed via metamodels; the resulting main characteristics are provided in Table 3. Analyzing the main dimensions and coefficients, it rises up that the podded ship, even though of smaller size, is less slender than the twin-skeg solution.

The main cause is the higher Froude number $(F n=0.26)$ for the twin-skeg ship at service speed of 23 knots, whereas the podded ship has $F n=0.24$. The different required capacities of the two solutions have a heavy impact on the ratio between cargo capacity and total displacement, which is reflected on the block coefficient too.

The difference between hull form shapes has led to obtain a better specific resistance for the twin-skeg ship in all the speed range, as shown in Figure 89. The same consideration is still valid when propulsive issues are considered. In fact, analysing the trial condition for the two ships, the following conclusion can be drawn for the two ships considering the different propulsive power mounted on board of each configuration as per Table 3.

For the twin-skeg concept, mounting a propeller with geometrical characteristics similar to the one of Table 3, a sustained speed of 24.45 knots is expected with propellers rotating at $124.0 \mathrm{rpm}$ absorbing a shaft power of $22304.5 \mathrm{~kW}$ without presence of wind and waves. Under the same conditions, a speed of 21.55 knots with propeller rotating at $203.8 \mathrm{rpm}$ with an available shaft power of $19601.0 \mathrm{~kW}$ is expected for the podded ship. It must be noted that the selected propellers parameters have been chosen searching for the design point at service speed, taking into account the added resistance evaluated in the Eastern Mediterranean sea. 


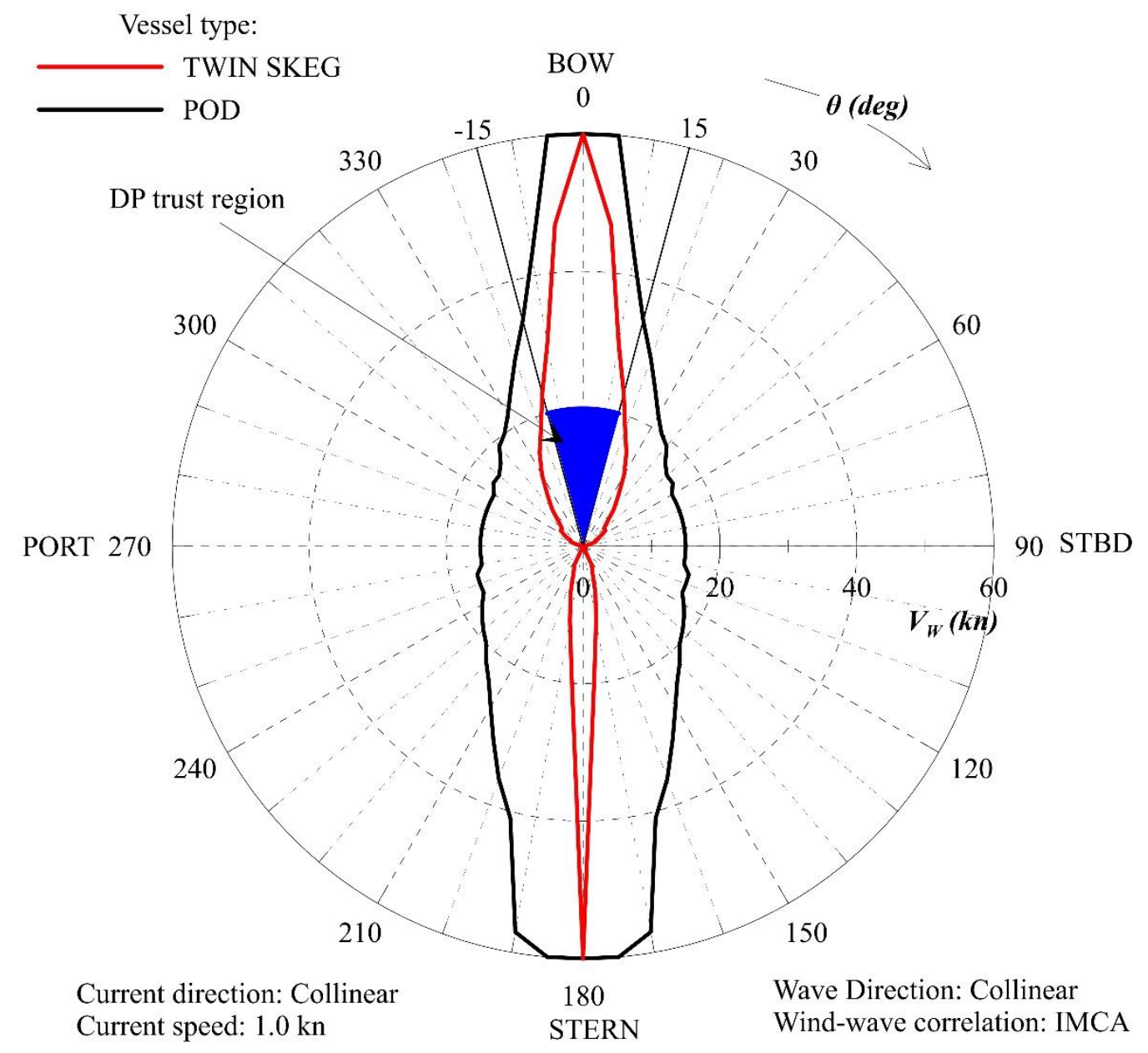

Fig. 10 Comparison between the capability plots of the two ships.

The results of the speed-power predictions on trials have been reported in Figure 9. It can be seen that the propulsive curve for the podded solution is rapidly becoming steeper after 21.5 knots. That is due to rising up of cavitation, which dramatically increases the propeller revolution rates and consequently the absorbed power.

Even though the two ship types intrinsically respect the DP constraints, which filter the feasible designs during the generation process, it is interesting to visualize the different capability plots [36] of the two optimal ships. The capability plot reports the maximum sustainable wind that the DP system can face at each encounter angle, making easy a reliable comparison between the station-keeping ability of the two ships. In Figure 10, the two DP capabilities of the two optimal ship concepts are presented on the same plot, highlighting significant differences.

In fact, while compliant with imposed DP constraints, the twin-skeg ship has lower capability with respect to the podded ship. This is quite reasonable to predict, since the propeller-plus-rudder configuration is giving less freedom to properly face the environmental loads, especially from stern encounter angles. For the specific operations near the buoy, it is reasonable to presume that the ship will always be oriented in a direction around $0 \mathrm{deg}$; that's why the constraint was assumed at 15 deg during the generation process of candidate ships. Given such a big difference between the two resulting capability plots, it should be then advisable to investigate whether the operability of the two ships will be reduced or not depending on the different configurations. 


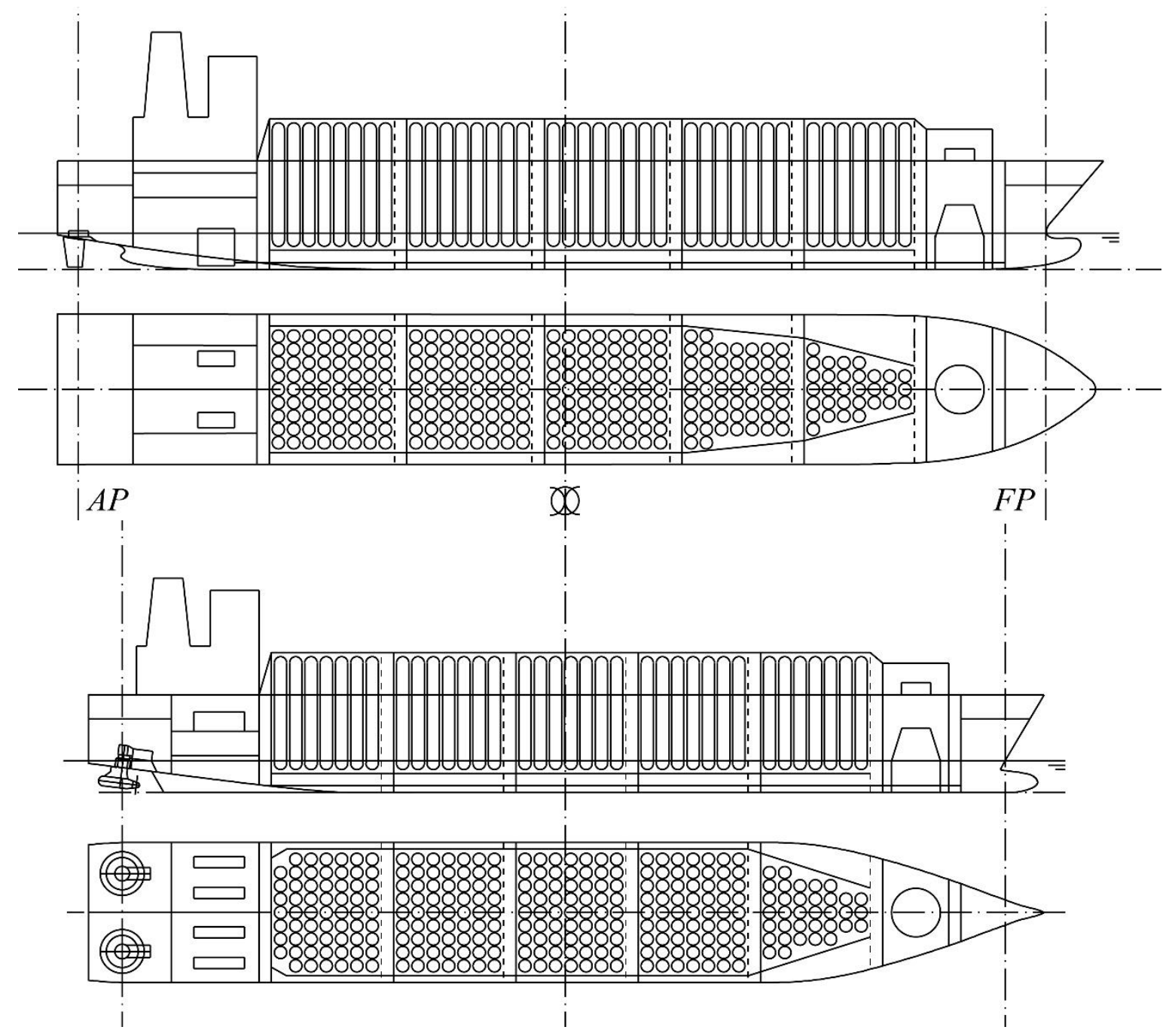

Fig. 11 Conceptual general arrangement of the twin-skeg (top) and pod (bottom) solutions.

At concept design stage it is hard to directly consider the effective downtime period due to adverse weather during DP operation, which is important for the logistic model described in Section 2. By doing a detailed analysis on the effective DP operability of the ship, then the downtime period could be better determined, improving the quality of the fleet determination. In fact, as mentioned, the logistic is considering the same downtime period for both ships. For such a reason, DP issue should be kept in serious consideration in further studies and analyses.

Besides pure hydrodynamic considerations, it is interesting to analyse the two different internal layouts coming from the conceptual design phase. As mentioned beforehand, the developed design method is suitable to analyse the internal layouts on the base of the primitive cargo units, fitting the most suitable holds configuration according to the ship dimensions. In Figure 11 it is possible to visualise the two resulting conceptual general arrangement plans which are strongly influenced by both cargo spaces and machinery spaces.

As highlighted in [18], the main constraint acting on cargo spaces is the waterline width at tank-top, since it is mandatory to assure a minimum distance of cargo holds from hull shell according to the International Gas Code. Both ships have a cargo space subdivided in 5 holds, but the number of PV per hold is higher for the twin-skeg ship. The maximum transversal number is 9 for both designs, since the differences in breadth between the two units did not allow installation of an additional PV for the twin-skeg case. However, the number of lines per hold is different, being 7 for the podded solution and 8 for the twin-skeg. It is also interesting 
to notice how the holds are disposed. The podded ship, having a relatively bigger parallel middle body, is suitable to have almost 4 fully loaded holds; on the contrary, the twin-skeg solution is having only three holds fully loaded, while the two foremost holds are strictly limited by the waterline width at tank-top. As discussed in subsection 4.3, the propulsive system has a strong influence on the general arrangement. In fact, the engine room for the podded ship is less extended compared to the twin-skeg solution, leading to a much shorter afterbody. The twinskeg ship, even though is slenderer, has a more extended parallel body ranging from section 8 to 10 , while it is limited to sections 8 and 10 in the podded ship.

\section{Conclusions}

A process aimed to determine an optimal CNG fleet has been presented, considering a specific transportation scenario in the Mediterranean Sea. Two different ship concepts have been conceived, designed at conceptual design level and analysed in techno-economic terms. Comparison between the shipping tariffs on the selected scenario for the optimal fleets composed by two ship concepts has highlighted that the twin-skeg solution has a lower tariff compared to the podded one. Analysing more in detail the two ship types composing the optimal fleets, it results that the twin-skeg solution presents better hydrodynamic performances with respect to the podded solution. The tariff evaluation of the podded ship shows some discontinuities that are due to the fact that pod size cannot be customized, but are roundly fixed by the manufacturers. The twin-skeg solution is not presenting this discontinuity since the propeller selection is more flexible. Also the dynamic positioning problem has been considered for the two solutions. Besides the constraints on a single DP criteria for an environmental condition and heading, the two ships composing the best fleets have been compared considering the capability plot. The analysis highlights that the podded solution has a higher capability with respect to the twin-skeg one, since the pod system is more flexible to balance the environmental and external load. The possibility to consider also DP inside the concept design stage has to be further analysed, since it can be source of a better definition of the ship operability. This is influencing the downtime period of the ships, relaxing the constraints in the logistic model.

The developed strategy for optimal fleet selection simultaneously provides the number of fleet's ships, the gas capacity and the economically service speed of each sister ship on the basis of minimising a shipping tariff at the expected rate of return.

\section{REFERENCES}

[1] ..., 2018, World Energy Balances (2018 edition), International Energy Agency, Paris, France.

[2] ..., 2016, International Energy annual 2016, DOE/EIA-0219, Energy Information Administration, Washington, USA.

[3] Economides, M.J. and Wood, D.A., 2009, The state of natural gas, Journal of Natural Gas Science and Engineering, 1(1-2), 1-13. http://dx.doi.org/10.1016/j.jngse.2009.03.005.

[4] Economides, M.J., Wang, X., Colafemmina, F. and Tomaselli, N.V., 2012, The optimization of natural gas transportation, Proceedings of Society of Petroleum Engineering, Hydrocarbon, Economics and Evaluation Symposium, Calgary, Canada. https://doi.org/10.2118/161583-MS.

[5] Chernyavs'ka, L. and Dorigoni, S., 2003, Transportation Modes of Natural Gas and Liberalization of Markets in Europe: Pipelines or LNG? (in Italian), Economia delle Fonti di Energia e dell'Ambiente, 2.

[6] Nikolaou, M, Wang, X. and Economides, M.J., 2013, Optimisation of compressed natural gas marine transportation with composite-Material containers, Proceedings of SPE Asia Pacific Oil and Gas Conference and Exhibition, Jakarta, Indonesia. https://doi.org/10.2118/165898-MS.

[7] Nikolaou, M., 2010, Optimizing the logistics of compressed natural gas transportation by marine vessels, Journal of Natural Gas Science and Engineering, 2(1), 1-20. https://doi.org/10.1016/j.jngse.2010.02.001.

[8] Wagner, J. V., van Wagensveld, S., et al.,2002. Marine transportation of compressed natural gas a viable alternative to pipeline or lng. In SPE Asia Pacific Oil and Gas Conference and Exhibition. Society of Petroleum Engineers. https://doi.org/10.2118/77925-MS. 
[9] Stenning, D. G., Fitzpatrick, J. P., Trebble, M. A., 2012, Floating CNG, a simpler way to monetise offshore gas. In Offshore Technology Conference. Offshore Technology Conference. https://doi.org/10.4043/23615-MS.

[10] Bortnowska, M., 2009, Development of new technologies for shipping natural gas by sea. Polish Maritime Research, 16(3):70-78. https://doi.org/10.2478/v10012-008-0036-2.

[11] Valsgård, S., Reepmeyer, O., Lothe, P., Strøm, N. K., and Mørk, K., 2004. The development of a compressed natural gas carrier. In 9th International Symposium on Practical Design of Ships and Other Floating Structures

[12] Trincas, G., 2018, Comparison of Marine Technologies for Mediterranean Offshore Gas Export, Proceedings of $19^{\text {th }}$ International Conference on Ship \& Maritime Research - NAV 2018, Trieste, Italy. http://dx.doi.org/10.3233/978-1-61499-870-9-577

[13] Trincas, G., 2014, Optimal fleet composition for marine transport of compressed natural gas from stranded fields, Proceedings of 1st INT-NAM Conference, Istanbul, Turkey.

[14] Vernengo, G. and Rizzuto, E., 2010, Ship synthesis model for the preliminary design of a fleet of compressed natural gas carriers, Ocean Engineering, 89, 189-199. https://doi.org/10.1016/j.oceaneng.2014.08.012.

[15] Gaggero, T., Vernengo, G., Parodi, M., and Rizzuto, E., 2018. Logistics-based fleet design for complex transportation scenarios. Ships and Offshore Structures, pages 1-16. https://doi.org/10.1080/17445302.2018.1454095.

[16] Vernengo, G., Gaggero, T. and Rizzuto, E., 2016, Simulation based design of a fleet of ships under power and capacity variations, Applied Ocean Research, 61, 1-15. https://doi.org/10.1016/j.apor.2016.09.003.

[17] Pugh, S. 1991, Total design: integrated methods for successful product engineering, Workingam.

[18] Trincas, G., Mauro, F., Braidotti, L., Bucci, V., 2018, Handling the path from concept to preliminary ship design, Proceedings of the $13^{\text {th }}$ International Marine Design Conference, IMDC 2018, Helsinki, Finland.

[19] Lothe, P., 2005. The Knutsen OAS shipping pressurized natural gas carrier (PNG). In The Fifteenth International Offshore and Polar Engineering Conference. International Society of Offshore and Polar Engineers.

[20] Mauro, F., Braidotti, L. and Trincas, G., 2018, Effect of Different Propulsion Systems on CNG Ships Fleet Composition and Economic Effectiveness, Proceedings of $19^{\text {th }}$ International Conference on Ship \& Maritime Research - NAV 2018, Trieste, Italy. http://dx.doi.org/10.3233/978-1-61499-870-9-398

[21] Trincas, G., Grubišić, I. and Žanić, V., 1994, Comprehensive concept design of fast ro-ro ships by multiattribute decision making. Proceedings of 5th International Marine Design Conference, IMDC'94, Delft, the Netherlands.

[22] Sevkli, M., 2009, An Application of the Fuzzy Electre Method for Supplier Selection, International Journal of Production Research 48(12), 3393-3405. https://doi.org/10.1080/00207540902814355.

[23] Myers R.H., Montgomery D.C and Anderson-Cook C.M., 2008, Response surface methodology - process and product optimization using designed experiments. Third edition, J. Wiley \& sons, Hoboken, USA.

[24] Lamb T., 2003, Ship Design and Construction, Vol. I, SNAME, Jersey City, USA.

[25] Apostolidis, A., Kokarakis, J., and Merikas, A., 2012, Modeling the Dry-Docking Cost - The Case of Tankers, Journal of Ship Production, Vol. 28, no. 3, pp. 134-143. https://doi.org/10.5957/JSPD.28.3.110039.

[26] Holtrop J., 1988, A statistical re-analysis of resistance and propulsion data, International Shipbuilding Progress 31(363), 272-276.

[27] Holtrop, J. and Mennen, G.G.J., 1982, An approximate power prediction method, International Shipbuilding Progress 29(335), 166-170. https://doi.org/10.3233/ISP-1982-2933501.

[28] Shifrin, L.S., 1973, AN Approximate Calculation of Added Resistance of Ship in Regular Waves. Sudostroenie, 12, 5-7 (in Russian).

[29] Kuipers, G., 1992, The Wageningen Propeller Series, $1^{\text {st }}$ edition, MARIN publication, Wageningen, The Netherlands.

[30] Mauro, F., and Duranti E., 2018, Effect of propeller modelling on station-keeping thruster allocation strategy, Proceedings of $19^{\text {th }}$ International Conference on Ship \& Maritime Research - NAV 2018, Trieste, Italy. http://dx.doi.org/10.3233/978-1-61499-870-9-356

[31] Nabergoj, R., 2011, Station keeping and seakeeping in offshore vessels design. Proceedings of $1^{\text {st }}$ INTNAM, Istanbul, Turkey. 
[32] Mauro, F. and Gaudiano, F., 2018, Station-keeping calculations in early design stage: two possible approaches. Proceedings of $19^{\text {th }}$ International Conference on Ship \& Maritime Research - NAV 2018, Trieste, Italy. http://dx.doi.org/10.3233/978-1-61499-870-9-372

[33] Serraris, J., 2009, Time-domain analysis for DP simulations, Proceedings of OMAE Conference, Honolulu, Hawaii. https://doi.org/10.1115/OMAE2009-79587.

[34] Smogeli, O., Trong, N., Borhaug, B. and Pivano, L., 2013, The next level DP capability analysis, Proceedings of Dynamic Positioning Conference.

[35] Mauro, F. and Nabergoj, R., 2015, Smart thrust allocation procedures in early design stage dynamic positioning predictions, Proceedings of $18^{\text {th }}$ International Conference on Ship \& Maritime Research NAV 2015, Lecco, Italy.

[36] ..., 2000, Specification for D capability plots, IMCA 140 rev.1, The International Marine contractors Association (IMCA).

[37] Mauro, F. and Nabergoj, R., 2016, Advantages and disadvantages of thrusters allocation procedures in preliminary dynamic positioning predictions. Ocean Engineering 123, 96-102. http://dx.doi.org/10.1016/j.oceaneng.2016.06.045

[38] ..., 2014, Guide for Dynamic Positioning Systems, American Bureau of Shipping (ABS).

[39] ..., 2018, Assessment of station keeping capability of Dynamic Positioning vessels, DNV-GL.

[40] Turk, A. and Prpić-Oršić, J., 2009, Estimation of extreme wind loads on marine objects, Brodogradnja 60(2), 147-156.

[41] Blendermann, W., 1996, Wind loading of ships- collected data from wind tunnel tests in uniform flow, technical Report 574, Institut für Shiffbau der Universität Hamburg.

[42] Isherwood, R.M., 1972, Wind resistance of merchant ships. The Royal Institution of Naval Architects 115, 327-338.

[43] Fujiwara, T. and Nimura, T., 2005, New estimation method for wind forces acting on ships on the basis of mathematical model. Proceedings of the $15^{\text {th }}$ International Offshore and Polar engineering Conference, Seoul, Korea.

Submitted: 13.12.2018. Francesco Mauro (*corresponding author), fmauro@units.it Luca Braidotti, $\underline{\text { lbraidotti@units.it }}$

Accepted: 23.05.2019. Giorgio Trincas, trincas@units.it Department of Engineering and Architecture, University of Trieste, Via Valerio 10, 34127 Trieste (Italy) 